$\mathbb{T}$ periodica polytechnica

Chemical Engineering

$51 / 2(2007) 13+17$

doi: 10.3311/pp.ch.2007-2.03

web: http://www.pp.bme.hu/ch

(c) Periodica Polytechnica 2007

RESEARCH ARTICLE

\section{Modelling of wastewater ozonation - determination of reaction kinetic constants and effect of temperature}

\author{
Edit Cséfalvay / Tobias Nöthe / Péter Mizsey
}

Received 2006-10-03

\begin{abstract}
The direct ozonation is more and more used for waste water treatment. In this study the effect of temperature on the direct ozonation of a wastewater is studied. At constant $p H$ and dissolved organic carbon concentration, the time-dependence of ozone concentration is measured in the function of different temperatures. Continuous experiments are carried out at two temperatures $\left(8\right.$ and $\left.17^{\circ} \mathrm{C}\right)$, batch experiments are carried out at three temperatures $\left(8,18\right.$ and $\left.27^{\circ} \mathrm{C}\right)$. It is shown that with increasing temperature the ozone depletion is faster in both cases. In case of batch experiments the temperature dependence of the reaction kinetic constant is measured. It is found that if the temperature is increased by $10^{\circ} \mathrm{C}$ doubles the value of the reaction kinetic constant.
\end{abstract}

\section{Keywords}

ozone $\cdot$ ozonation $\cdot$ temperature-dependence $\cdot$ reaction kinetic constant $\cdot$ wastewater

\section{Edit Cséfalvay}

Department of Chemical and Environmental Process Engineering, BME, H1111, Budapest, Múegyetem rkp. 3., Hungary

e-mail: csefalvay@ch.bme.hu

\section{Tobias Nöthe}

Department of Environmental Technology, Dortmund University,, Germany

\section{Péter Mizsey}

Department of Chemical and Environmental Process Engineering, BME, H1111, Budapest, Múegyetem rkp. 3., Hungary

\section{Introduction}

In recent years the ozonation process has been widely studied, not only its applicability in water treatment (e.g. disinfection of drinking water, removal of pollutants from wastewater) but the reaction kinetics of these processes has been the centre of the scientific research. In the ozonation of drinking- and wastewater, ozone may decompose through self-decomposition or via reactions. Ozone molecules may initiate a complicated chain of oxidation reactions. In aqueous medium the ozonation reaction may follow two pathways: direct oxidation and indirect free hydroxyl radical oxidation reactions may take place. These reactions take place simultaneously. The formed free hydroxyl radicals are not selective: they can react not only with ozone, but with every compound being in water. In such reactions other end products or other radicals can be formed. Parameters like temperature, $\mathrm{pH}$, the Dissolved Organic Carbon (later on DOC) concentration and presence of scavengers influence these complex oxidation and decomposition reactions. With the help of radical scavengers (e.g. carbonates) the direct ozone reactions can be studied [1]. The effects of influential parameters are dealt with in several papers [2]-[3]. Erlovitz et al. [2] studied the hydroxyl radical/ozone ratio during the ozonation processes and took into consideration the effect of temperature, $\mathrm{pH}$, alkalinity and dissolved organic matter properties. Buffle et al. [3] examined the effect of ozone dose, $\mathrm{pH}$, dissolved organic matter and hydroxyl radical scavengers on ozonation.

Several studies deal with the application of ozonation e.g. disinfection of drinking water [1, 4,5]. The reduction of pollutants by ozone in wastewater treatment is also relevant [6]-[10]. A recently published review gives a broad overview of ozonation and Advanced Oxidation Processes (AOP) via the degradation of aqueous pharmaceuticals [11].

\subsection{Theoretical Background}

Ozone is a very reactive chemical, therefore, it can be used as a powerful oxidizing agent to remove the pollutants from water. Ozone reacts with the oxidizable components (marked with $\mathrm{C}_{i}$ ) 
in direct reactions:

$$
\begin{gathered}
\mathrm{O}_{3}+C_{i} \stackrel{k_{c_{i}}}{\longrightarrow} C_{\text {oxidized }} \quad 0<k_{C i} \leq 10^{3} \mathrm{~L} \cdot \mathrm{mol}^{-1} \cdot \mathrm{s}^{-1} \\
\mathrm{O}_{3}+C_{i} \stackrel{k_{r}}{\longrightarrow} \mathrm{OH}^{\bullet}+O P
\end{gathered}
$$

As it is shown above, the direct oxidation reactions of oxidizable compounds can lead either to stable end product marked with $C_{\text {oxidized }}$ (see Eq. 1) or to free hydroxyl radicals and other products marked with OP (see Eq. 2). The formed hydroxyl radicals react with ozone (see Eq. 3), so increase the ozone consumption. The radicals oxidize the oxidizable components too, and so end products and other radicals are formed. Eqs. 4 and 5 represent the indirect oxidation of the pollutants in ozonation.

$$
\begin{array}{r}
\mathrm{O}_{3}+\mathrm{OH}^{\bullet} \stackrel{k_{7}}{\longrightarrow} \mathrm{HO}_{2}^{\bullet}+\mathrm{O}_{2} \\
k_{7}=10^{9}[12] \text { or } 10^{10} \mathrm{~L} \cdot \mathrm{mol}^{-1} \cdot \mathrm{s}^{-1}[13] \\
\mathrm{C}_{i}+\mathrm{OH}^{\bullet} \longrightarrow \mathrm{HO}_{2}^{\bullet}+\mathrm{C}_{\text {oxidized }} \\
\mathrm{C}_{i}+\mathrm{OH}^{\bullet} \longrightarrow \mathrm{C}_{\text {oxidized }}
\end{array}
$$

Formed radicals can be eliminated by using scavengers. Scavengers have high reaction affinity to radicals, mainly to hydroxyl radicals, therefore, radicals react preferably with scavengers rather than with the oxidizable components or ozone. In this way direct oxidation reaction comes to the front. Depending on the quality and quantity of the oxidizable components and also the reaction's temperature, $\mathrm{pH}$ and concentration of scavengers the reaction time changes from seconds to minutes. Fig. 1 shows two schematic drawings of depletion of ozone concentration in case of natural- $(a)$ and wastewater $(b)$ ozonation at a given ozone dose and at constant circumstances.

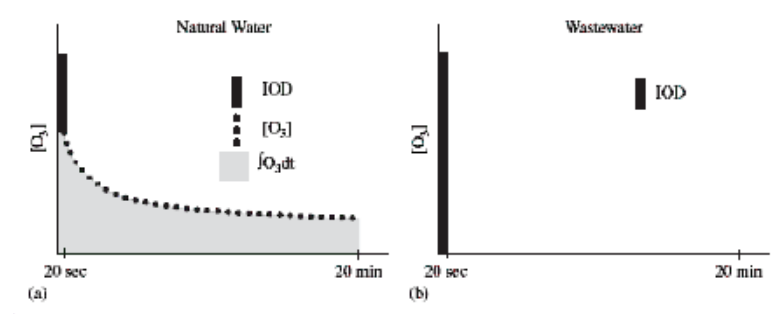

Fig. 1. A schematic example of ozone depletion in natural water (a) and wastewater (b) at constant temperature and $\mathrm{pH}$

It can be seen in Fig. 1. a) that at relatively low DOC concentration (represented by natural water) ozone depletion is characterized by a fast initial decrease of ozone, followed by a second phase, in which ozone decreases by first order kinetics. In case of wastewater (see in Fig. 1(b)) using the same ozone dose, all the ozone disappears within a short time. The amount of ozone consumed within 20 seconds is defined as Instantaneous Ozone Demand (IOD) and is typically represented by a straight vertical line in concentration versus time.
The reaction rates of both the initial and the second phases can be determined by experiments. The determination of the reaction rate of the initial phase can be attained by competition kinetics. Hydroxyl radicals possess remarkably higher reaction rate constants to scavengers than to ozone. If the scavengers form a sufficient long-lived intermediate and its concentration is measurable, and also the concentration of ozone and the scavenger is known, then the reaction kinetic constant of the ozone can be calculated [14]. Determination of the reaction rate in the second phase is simpler. The scavenger added to the reaction mixture reacts with hydroxyl radicals, so the ozone consumption is determined by the concentration of the oxidizable components. From the time dependence of the ozone concentration the reaction rate constant of the ozone reaction can be calculated.

\subsection{Aim of the Work}

The aim of the work is to characterize the ozone consumption of an effluent of a wastewater treatment plant both in the initial and in the second phases. Since the effluent of a wastewater treatment plant is treated water, its DOC concentration is similar to that of the natural waters. Therefore, during ozonation the two phases of ozonation can be observed and examined (Fig. 17). In the initial phase continuous measurements are carried out at two temperatures in order to determine the effect of temperature on the ozone concentration during ozonation of the treated wastewater. Batch experiments are carried out at three different temperatures in order to determine the temperature-dependence of ozone depletion and the temperature-dependence of the first order reaction rate.

\section{Experimental}

Effluent of a wastewater treatment plant is treated by ozone. Two types of experiments are carried out: continuous measurements in order to study the initial phase using a stopped-flow module, and batch experiments in order to study the reaction kinetics of the second phase of ozone depletion. In both cases the reaction takes place in aqueous environment. Ozone dissolved in water reacts with the oxidizable components of the wastewater effluent. The dissolved ozone and the treated wastewater are prepared the same way for all the experiments.

\subsection{Generation of Dissolved Ozone}

A schematic drawing of ozone generation can be seen in Fig. 2. Ozone is produced from oxygen gas in a Wedeco type ozone generator by means of a silent electrical discharge. Direct current is applied between two concentrically arranged electrodes. The electrodes are separated from each other by oxygen filling the two discharge chambers, through which the gas flows. Some of the oxygen molecules in the input gas break down in the electric field and immediately attach themselves to free oxygen molecules, forming ozone. The formed ozone gas is bubbled into cool water. To increase the quantity of the absorbed ozone, 
the cryostat is adjusted to $0.5^{\circ} \mathrm{C}$. The barbotage lasts 15 minutes in every case. The concentration of the generated ozone solution is $11.5 \pm 0.5 \mathrm{mg} \cdot \mathrm{L}^{-1}$.

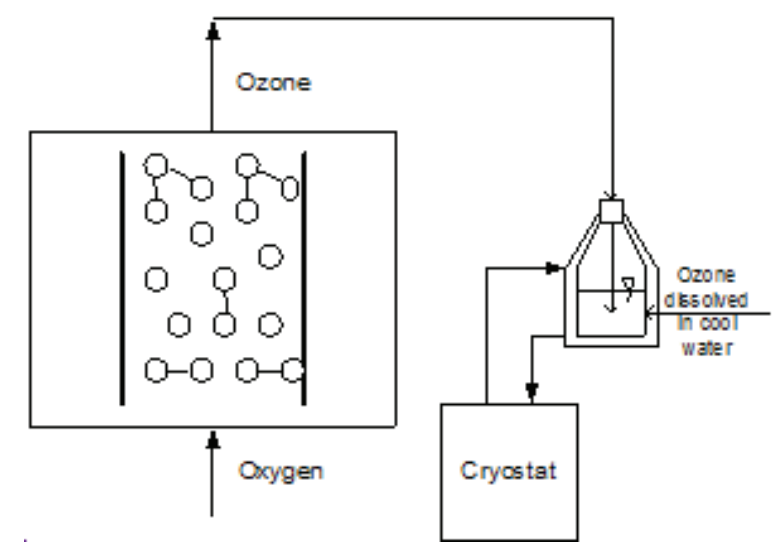

Fig. 2. Schematic drawing of the process of ozone generation

\subsection{Preparation of Wastewater}

The sample of the effluent of a wastewater treatment plant is filtered through a microfiltration membrane with a porediameter of $0.45 \mu \mathrm{m}$ to remove the floating pollutants. After the removal of floating pollutants the wastewater is stored in a refrigerator at $4^{\circ} \mathrm{C}$ until the experiment begins, in order to avoid any change in composition. The DOC-value of the wastewater is $9.09 \mathrm{mg} \cdot \mathrm{L}^{-1}$ and the $\mathrm{pH}$ is $8 \pm 0.1$. At every experiment the $\mathrm{pH}$ is adjusted to 8.00 to ensure comparable results. Alkalinity is determined by the German Standard [15], therefore, it is expressed by carbonate hardness. The carbonate hardness of the prepared wastewater is found to be $13.3^{\circ} \mathrm{d}$. Carbonate and bicarbonate ions belong to scavengers, but in this case their quantity is not sufficient to scavenge all the radicals. Therefore, the carbonate and bicarbonate content of the sample is eliminated by hydrochloric acid. Due to the acid carbon-dioxide arises and leaves the sample. Tert-butanol regarded as a very efficient radical scavenger, is added to the wastewater. $3.46 \mathrm{~mL}$ tert-butanol is added to $1000 \mathrm{~mL}$ wastewater in case of every experiment.

\subsubsection{Continuous Measurements}

Using a stopped-flow module continuous measurement of the ozone concentration during the initial phase is investigated. The schematic drawing of the stopped-flow module can be seen in Fig. 3. The prepared wastewater is filled into funnel $S$ and the ozone solution is filled into funnel $O$. The standard (distilled) water is filled into funnel St. In the stopped-flow module a onecentimeter-wide cuvette is located, where the oxidation reaction takes place. The decrease of ozone concentration can be measured by UV spectrometry. The cuvette is filled with the mixture of a standard and of an ozone solution at first and the absorption of ozone is measured at $254 \mathrm{~nm}$ wavelength. After cleaning the cuvette, it is filled with wastewater-ozone solution mixture. During the ozonation reaction the absorption of ozone is measured in every 0.04 seconds. Data are sent to the computer, which calculates the concentration of ozone by the Lambert-Beer law. The extinction factor of ozone is $3300 \mathrm{~L} \cdot \mathrm{mol}^{-1} \cdot \mathrm{cm}^{-1}$.

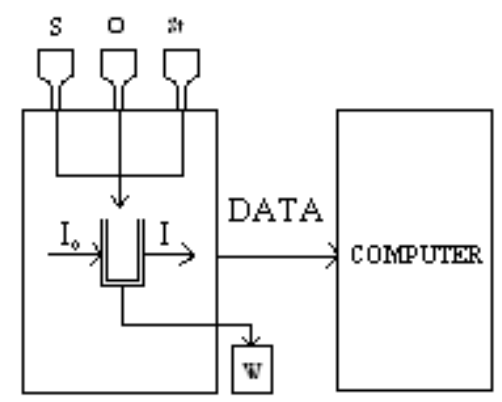

Fig. 3. Schematic drawing of the stopped-flow module

\subsubsection{Batch Experiments}

In order to determine the reaction rate constants in the second phase of ozonation and to measure the ozone concentration during oxidation batch experiments are carried out in a reaction glass. Batch experiments are carried out at three different temperatures: $8,18,27^{\circ} \mathrm{C}$. The prepared wastewater samples have the following properties: $\mathrm{pH}=8.00$, tert-butanol (scavenger) content $=3.46 \mathrm{~mL} \cdot L^{-1}$, DOC $=9.09 \mathrm{mg} \cdot L^{-1}$. After reaching the given temperature, the dissolved ozone is added to the prepared wastewater. At regular intervals samples are taken from the reaction mixture in order to determine the concentration of ozone by the indigo method [16].

\subsection{Analytics}

Since the experiments are carried out in the laboratory of the Department of Environmental Technology, Dortmund University, Germany the analytical methods are mainly based on the German Standard.

Ozone concentration is determined either by a UV spectrometry or by the indigo method [16]. In the stopped-flow module the absorbance of ozone molecules at $254 \mathrm{~nm}$ is measured, therefore, direct determination of ozone concentration is achieved. The indigo method is an indirect determination of ozone concentration. Ozone reacts with indigo-trisulfonate and discolours the solution. The absorbance of indigo-trisulfonate can be measured at $600 \mathrm{~nm}$. In this way indirect determination of ozone concentration is carried out. Measurement of alkalinity is investigated by the German Standard [15].

\section{Results and Discussion}

\subsection{Continuous Measurements}

Effect of temperature on ozone concentration in the initial phase of ozonation is shown in Fig. 4 at two different temperatures. The initial concentration of ozone is $11.5 \mathrm{mg} \cdot \mathrm{L}^{-1}$. The curves are very similar; however at $17^{\circ} \mathrm{C}$ the curve of ozone concentration runs below the curve of ozone concentration at $8^{\circ} \mathrm{C}$. The ozone depletion is faster at higher temperatures. 


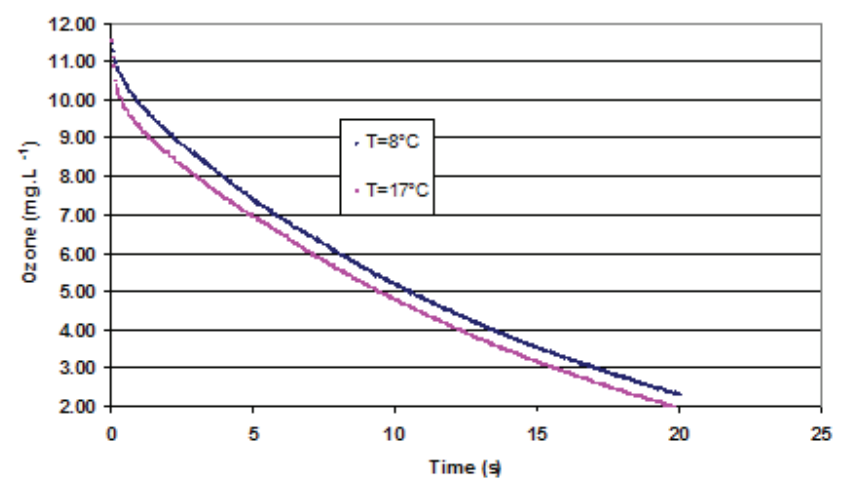

Fig. 4. Effect of temperature on ozone decomposition in wastewater $(\mathrm{pH}=8$ and DOC $=9.099 \mathrm{mg} \cdot \mathrm{L}^{-1}$ ) in the stopped-flow module

\subsection{Batch Experiments}

Fig. 5 shows the change in ozone concentration in the second phase at three different temperatures.

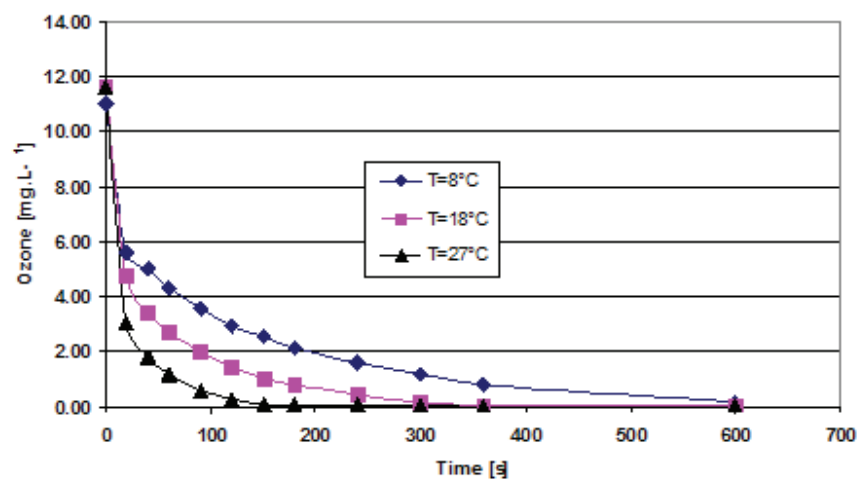

Fig. 5. Effect of temperature on ozone decomposition in wastewater $(\mathrm{pH}=8$ and DOC $\left.=9.09 \mathrm{mg} \cdot \mathrm{L}^{-1}\right)$ in batch experiments

Comparing the ozone concentration decrease in the initial and in the second phase, a significant temperature-dependence can be observed. With increasing temperature, the time moment when the ozone totally disappears is reduced. Namely at $8^{\circ} \mathrm{C}$ the ozone disappears after 600 seconds, while at $27^{\circ} \mathrm{C}$ the ozone disappears at around 200 seconds.

The time-dependence of ozone concentration can be modelled by a simple first order differential equation.

$$
\frac{d c}{d t}=-k_{f} \times c
$$

where $k$ is a function of the temperature. The minus sign represents that the ozone concentration decreases in time. Solving the differential equation, regarding the marginal conditions of $c_{0}$ as the initial concentration of ozone, the following equation is developed:

$$
-\ln \left(\frac{c}{c_{0}}\right)=k_{f} \times t+\text { const }
$$

Plotting on a diagram the left hand side of Eq. 7 versus time, the slope of the straight line gives the reaction kinetic constant. As Fig. 6 shows, regarding the second phase of ozonation the measured points really fit a straight line, showing that the ozone is decomposed according to first order kinetics. Fig. 6 also shows the effect of temperature on the reaction kinetic constant in the second phase. It can be seen, that the higher the temperature the steeper is the fitted line, i.e. at higher temperatures ozone depletion is faster.

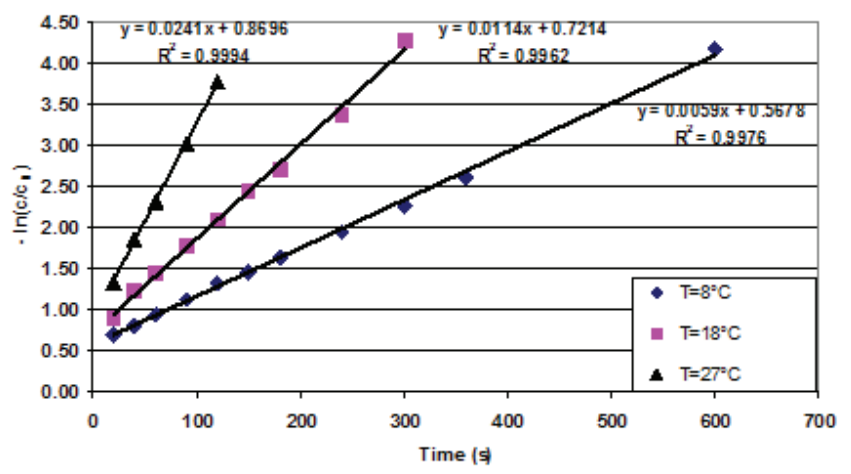

Fig. 6. Effect of temperature on the reaction kinetic constant in batch experiments $\left(\mathrm{pH}=8\right.$ and DOC $\left.=9.09 \mathrm{mg} \cdot \mathrm{L}^{-1}\right)$

Tab. 1. Effect of temperature on the reaction kinetic constant in batch experiments $\left(\mathrm{pH}=8\right.$ and $\left.\mathrm{DOC}=9.09 \mathrm{mg} \cdot \mathrm{L}^{-1}\right)$

\begin{tabular}{cc}
\hline Temperature $\left({ }^{\circ} \mathrm{C}\right)$ & Reaction kinetic constant $\left(s^{-1}\right)$ \\
\hline 8 & 0.0059 \\
18 & 0.0114 \\
27 & 0.0241 \\
\hline
\end{tabular}

Depending on the molecular structure of the oxidizable compounds, the reaction kinetic constant may range from less than 1 to about $10^{3} \mathrm{~L} \cdot \mathrm{mol}^{-1} \cdot \mathrm{s}^{-1}[1]$. Hoigné et al. [17] studied the rate constants of reactions of ozone with several substituted benzenes and carbohydrates. The kinetics of all the reactions studied could be regarded as first order kinetics. They found the rate constants in the range of $10^{-2}$ to $10^{-5} \mathrm{~L} \cdot \mathrm{mol}^{-1} \cdot \mathrm{s}^{-1}$. In our case the reaction can also be regarded as first order as it can be seen in Fig. 6 According to Eq. 7 the reaction kinetic constant must be given in $\mathrm{s}^{-1}$ unit. The reaction kinetic constants experimented are $0.0059 s^{-1}$ at $8^{\circ} \mathrm{C}, 0.0114 s^{-1}$ at $18^{\circ} \mathrm{C}$ and $0.0241 \mathrm{~s}^{-1}$ at $27^{\circ} \mathrm{C}$ at $\mathrm{pH}=8$ and DOC $=9.09 \mathrm{mg} \cdot \mathrm{L}^{-1} \cdot \mathrm{s}^{-1}$.

\section{Conclusions}

Effect of temperature on ozone concentration in case of wastewater ozonation is studied. Continuous measurements using a stopped-flow module and batch experiments are carried out. In case of continuous measurements the initial phase of ozone consumption is studied at two different temperatures $(8$ and $17^{\circ} \mathrm{C}$ ). In case of batch experiments not only the degree of ozone depletion is determined but the reaction rate constants are calculated too. In case of batch experiments at $8,18,27^{\circ} \mathrm{C}$ are carried out. All experiments are carried out at a constant $\mathrm{pH}$ of 8. Effluent of a wastewater treatment plant is used for to the experiments ( $\mathrm{DOC}=9.09 \mathrm{mg} \cdot \mathrm{L}^{-1}$ ). To avoid the indirect oxidation reactions, tert-butanol as scavenger is added to each sample 
in a given quantity. The reaction kinetic constants calculated at batch experiments are found to be $0.0059 s^{-1}$ at $8^{\circ} \mathrm{C}, 0.0114 s^{-1}$ at $18^{\circ} \mathrm{C}$ and $0.0241 s^{-1}$ at $27^{\circ} \mathrm{C}$. It is found that if the temperature increases by $10^{\circ} \mathrm{C}$ doubles the value of the reaction kinetic constant.

\section{List of Symbols}

$C_{i}$ oxidizable components

$C_{\text {oxidized }} \quad$ Oxidized components

OP Other product

AOP Advanced Oxidation Process

IOD Instantaneous Ozone Demand

DOC dissolved organic carbon $\left[m g \cdot L^{-1}\right]$

COD chemical oxygen demand $\left[m g \cdot L^{-1}\right]$

$c \quad$ concentration of ozone $\left[\mathrm{mg} \cdot \mathrm{L}^{-1}\right]$

$c_{0} \quad$ initial concentration of ozone $\left[\mathrm{mg} \cdot \mathrm{L}^{-1}\right]$

$t \quad$ time (s)

$k \quad$ reaction kinetic constant (mentioned in literature) $\left[L \cdot \mathrm{mol}^{-1} \cdot \mathrm{s}^{-1}\right]$

$k_{f} \quad$ first order reaction kinetic constant $\left(s^{-1}\right)$

$L \quad$ litre $\left(\mathrm{dm}^{3}\right)$

\section{References}

1 Yurteri C, Gurol MD, Ozone Consumption in Natural Waters: Effect of Background Organic Matter, $p H$ and Carbonate Species, Ozone-Sci Eng 10 (1988), no. 3, 277-290.

2 Erlovitz MS, Von Gunten U, Kaiser HP, Hydroxyl radical/ozone ratio during ozonation processes. II.: The effect of temperature, $\mathrm{pH}$, alkalinity and DOM properties, Ozone-Sci Eng 22 (2000), no. 2, 123-150.

3 Buffle MO, Schumacher J, Meylan S, Jekel M, Von Gunten U, Ozonation and advanced oxidation of wastewater: Effect of $\mathrm{O}_{3}$ dose, $\mathrm{pH}, \mathrm{DOM}$ and $\mathrm{HO}$-scavengers on ozone decomposition and $\mathrm{HO}$ generation, Ozone-Sci Eng 28 (2006), no. 4, 247-259.

4 Guay C, Rodrigez M, Sérodes J, Using ozonation and chloramination to reduce the formation of trihalomethanes and haloacetic acids in drinking water, Desalination 176 (2005), no. 1-3, 229-240.

5 Schlichter B, Mavrov V, Chmiel H, Study of a hybrid process combining ozonation and microfiltration/ultrafiltration for drinking water production from surface water, Desalination 168 (2004), 307-317.

6 Wert EC, Rosario-Ortiz FL, Drury DD, Snyder SA, Formation of oxidation byproducts from ozonation of wastewater, Water Res 41 (2007), no. 7, 1481-1490.

7 Cañizuares P, Lobato J, Paz R, Rodrigo MA, Sáez C, Advanced oxidation processes for the treatment of olive-oil mills wastewater, Chemosphere 67 (2007), no. 4, 832-838.

8 Sangave PC, Gogate PR, Pandit AB, Combination of ozonation with conventional aerobic oxidation for distillery wastewater treatment, Chemosphere 68 (2007), no. 1, 32-41.

9 Dodd MC, Buffle M-O, Von Gunten U, Oxidation of antibacterial molecules by aqueous ozone: Moiety-specific reaction kinetics and application to ozone-based wastewater treatment, Environ Sci Technol 40 (2006), no. 6, 1969-1977.

10 Huber MM, Gobel A, Joss A, Hermann N, Loffler D, Mcardell CS, Ried A, Siegrist H, Ternes TA, Von Gunten U, Oxidation of pharmaceuticals during ozonation municipal wastewater effluents: a pilot study, Environ Sci Technol 39 (2005), no. 11, 4290-4299.

11 Ikehata K, Naghashkar NJ, El-Din MG, Degradation of aqueous pharma- ceuticals by ozonation and Advanced Oxidation Processes: A Review, OzoneSci Eng 28 (2006), no. 6, 353-414.

12 Bahnemann D, Hart EJ, Rate constants of the reaction of the hydrated electron and hydroxyl radical with ozone in aqueous solution, J Phys Chem 86 (1982), no. 2, 252-255.

13 Farhataziz-Ross AB, Selected specific rates of reactions of transients from water in aqueous solution: Report No. NSRDS-NBS59 (Washington DC: National Bureau of Standards), 1977.

14 Muñoz F., Von Sonntag C, Determination of fast ozone reactions in aqueous solution by competition kinetics, J. Chem. Soc., Perk T. II (2000), no. 4, 661-664.

15 DIN 38409 part 7: 2005 German standard methods for the examination of water, waste water and sludge: Determination of acid and base capacity.

16 DIN 38408 part 3: 2005 German standard methods for the examination of water, waste water and sludge - Gaseous components (group G) - Determination of ozone.

17 Hoigné J, Bader $\mathbf{H}$, Rate constants of reactions of ozone with organic and inorganic compounds in water-I: Non-dissociating organic compounds, Water Res 17 (1983), no. 2, 173-183. 